DOI 10.37882/2223-2982.2021.04.17

\title{
ИСПОЛЬЗОВАНИЕ ОПИСАТЕЛЬНОГО СПОСОБА ПЕРЕВОДА ПРИ ПЕРЕДАЧЕ ФРАЗЕОЛОГИЧЕСКИХ ЕДИНИЦ ПРОЗЫ Б.Л. ПАСТЕРНАКА НА АНГЛИЙСКИЙ ЯЗЫК
}

\section{THE USE OF DESCRIPTIVE TRANSLATION METHOD IN TRANSLATING \\ B.L. PASTERNAK'S PROSE \\ PHRASEOLOGICAL UNITS INTO ENGLISH \\ L. Kozhanova}

Summary: The article deals with the descriptive method of translation in translating the phraseological units of B.L. Pasternak's prose from Russian into English. Both the positive and negative aspects of using this method in the translation of phraseological units are analyzed. It is noted that when using a descriptive method of translation, the translator manages to convey not only the meaning of a phraseological unit, but also its expressiveness and stylistic coloring. The material considered showed that the translation of a significant number of Russian phraseological units by English lexical means is caused, first of all, by the absence in the translation language of phraseological adequacies - equivalents and analogues.

Keywords: phraseological units, descriptive method of translation, prose works, texts of translation, expressiveness, stylistic coloring.
Кожанова Лариса Владимировна

К.филол.н., дочент, ФГБОУ ВО «Воронежский государственный университет инженерных технологий»

l.kozhanova@bk.ru

Аннотация: В статье проводится рассмотрение описательного способа перевода при передаче фразеологических единиц прозы Б.Л. Пастернака с русского языка на английский. Анализируются как положительные, так и отрицательные стороны применения данного способа при переводе фразеологических единиц. Отмечается, что при применении описательного способа перевода переводчику удается передать не только значение фразеологической единицы, но также ее экспрессивность и стилистическую окраску. Рассмотренный материал показал, что передача значительного количества русских фразеологических единиц английскими лексическими средствами вызвана, прежде всего, отсутствием в языке перевода фразеологических соответствий - эквивалентов и аналогов.

Ключевые слова: фразеологические единицы, описательный способ перевода, прозаические произведения, тексты перевода, экспрессивность, стилистическая окраска.

бежны ощутимые потери: образа, оттенков значения ФЕ и его актуализации, коннотации.

На «неминуемые жертвы» при описательном переводе указывает А.В. Федоров и другие исследователи [7]. А.В. Кунин считает этот прием наименее эффективным из всех видов перевода, «так как он хотя и дает возможность передать семантику оборота, но лишает его красочности...» [4; 98]. Таким образом, эмоционально-художественное воздействие образных выражений в процессе описательного перевода заменяется «предметно-логической информацией» [1; 37].

Целью нашего исследования является рассмотрение описательного способа перевода при передаче ФЕ прозы Б.Л. Пастернака с русского языка на английский. В своем исследовании мы определяем описательный перевод как объяснение ФЕ языка подлинника с помощью свободного сочетания слов или одного слова при полной потере образа фразеологизма.

При этом автор данной статьи придерживается понимания фразеологии в широком смысле вслед за Н.М. Шанским, В.Л. Архангельским, М.М. Копыленко, 3.Д. Поповой и некоторыми другими учеными-языкове- 
дами. Пословицы, поговорки и крылатые слова признаются фразеологическими единицами.

В 818 контекстах мы находим использование описательного перевода ФЕ прозы Б.Л. Пастернака на английский язык. Эти многочисленные примеры показывают, что переводчики предпочли точное воссоздание смысла ФЕ подлинника передаче их образов и стилистической окраски.

Было отмечено, что чаще всего значение пастернаковского выражения передается с помощью слова или словосочетания, например:

«У Лары подкашивались ноги. Ее держали за руки, чтобы она не упала, и с трудом дотащили до ближайшего кресла, в которое она и рухнула» [6; 98].

«Lara was fainting, they were holding her up and almost carrying her to the nearest armchair where she finally collapsed» $[9 ; 85]$.

или

«Потомственные железнодорожники Тиверзины были легки на подъем и разъезжали по всей России по даровым служебным удостоверениям» [6; 47].

"... the Tiverzins, hereditary railway workers, were natural travellers and journeyed all over Russia on free service warrants» $[9 ; 40]$.

Нередко при переводе одного и того же фразеологизма переводчики используют различные лексические средства.

\section{Сравним:}

1. «Осенью движение армии приостановилось. Войска окапывались. Но об Антипове по-прежнему не было ни слуху ни духу» [6; 122].

«But in the autumn the advance slowed down, the troops were digging themselves in, yet there was still no word from him» $[9 ; 106]$.

2. «Но за истекшие месяцы того и след простыл, и о его выздоровевшей жене тоже не было ни слухуни духу» [6; 214].

«... but in the interving months the young man disappeared and nothing was known about his wife either» $[9 ; 187]$.

Однако не всегда переводчикам удается с помощью описательного перевода точно воспроизвести семантику русской ФЕ. Нередко значения русских образных выражений искажаются, так значение разговорной ФЕ как по маслу - без затруднений, легко и свободно (идти, развиваться и т.п.) в следующем примере: «Некоторое время все шло как по маслу. Шкап постепенно вырастал на глазах у Анны Ивановны» [6; 76] передается в переводе стилистически нейтральной лексемой well - хорошо: «At first everything went well. The cupboard grew in front of Anna's eyes...» $[9 ; 66]$.
Переводчики употребили лексему вместо ФЕ, несмотря на то что в английском языке имеется фразеологический аналог it is plain (plane, smooth, easy) sailing - букв.: легкое, ровное плавание.

Или же, при переводе русской ФЕ нейтральным английским словосочетанием in public утрачивается такое свойство ФЕ как экспрессивность, например:

«... она выругалась и погрозила кулаком удалявшейся кавалерии, возмущенная тем, как это ее старуху, осмелились при всем честном народе вытянуть плеткой» $[6 ; 51]$.

"... she swore and shook her fist at the retreating horsemen, indignant that they had dared to strike an old woman like herself, and in public at that» $[9 ; 43]$.

Не передана экспрессивная окраска и у ФЕ не в своей тарелке в английском переводе в следующем примере:

«Шурочка, бессознательно привыкший к тому, что все его ребяческие изречения на детском языке принимаются взрослыми восторженно, и потому, подлаживаясь под их вкус, с увлечением и охотно несший околесину, был не в своей тарелке» [6; 283].

«Sasha, who unconsciously expected to hear his childish utterances greeted with raptures and therefore prattled obligingly, was upset because for once he had no success, no one took any notice of him» $[9 ; 248]$.

Хотя в английском языке имеются аналоги feel like a fish out of water; be in the wrong box, обладающие экспрессивной окраской и имеющие то же значение, что и русская ФЕ.

Часто применение описательного перевода русских ФЕ на английский язык приводит к утрате ими оттенков значения, метафоричности и экспрессивности, отчего снижается художественная ценность текста перевода, а в конечном итоге, и пастернаковского текста - в том виде, в котором он предстает перед английскими читателями.

Перевод нередко уступает оригиналу по выразительности, экспрессивности. Так, громековский родственник седьмая вода на киселе [6; 189] Гогочка просто превращен в их дальнего родственника this to a distant relation of the Gromekos [9; 165]; как в воду опущенный [6; 182] Юрий Андреевич - просто в подавленного depressed [9; 160] человека; а не напетый с чужого голоса [6; 259] фанатизм Стрельникова - в its fanaticism, neither borrowed or accidental [9; 225] - букв.: фанатизм незаимствованный или случайный.

Английский читатель не воспринимает такие переводы выражений языка-источника как фразеологические.

Однако при анализе перевода фразеологизмов описательными средствами нельзя говорить исключитель- 
но о недочетах и потерях. К несомненным удачам переводчика можно отнести такие случаи, когда переводчику удается передать не только значение ФЕ, но и такие важные показатели контекста как экспрессивность и стилистическую окраску.

Так, межстилевая ФЕ между тем сохраняет свою нейтральность и при переводе на английский язык словом meanwhile, например:

«А меж тем то, что раньше понудило ее уйти в купе к старшим, однообразно продолжалось...» [5; 69].

«But meanwhile that which had compelled her to enter the compartment with the older people monotonously continued...» $[8 ; 177]$.

К несомненным удачам переводчиков стоит отнести и описательный перевод таких междометных фразеологических единиц как: Вот так фунт! Батюшки светы! Например:

1. «Вот так фунт! - подумал Живаго. - Чудак, повидимому, привык разговаривать только при полном освещении» [6; 169].
«What an extraordinary character!» thought Yury. «An eccentric evidently. Doesn't talk in the dark!» [9; 147].

2. «Ой батюшки светы, дорогие товарищи, что с нами сделалось, войдите в наше положение!» [6; 514]. «O, Lord almighty, dear comrades, the state we were in - put ourselves in our place!» $[9 ; 460]$.

Рассмотренный материал показал, что передача значительного количества русских ФЕ английскими лексическими средствами вызвана, прежде всего, отсутствием в языке перевода фразеологических соответствий - эквивалентов и аналогов. Особенно это касается перевода национально окрашенных ФЕ, а также фразеологизмов, имеющих дополнительное содержание (коннотацию) различные экспрессивно-эмоционально-оценочные стилистические оттенки.

Несмотря на ощутимые потери в образности, выразительности, красочности, использование описательного перевода часто позволяет достаточно точно передать значение и эмоционально-экспрессивную характеристику ФЕ подлинника.

\section{ЛИТЕРАТУРА}

1. Бархударов Л.С., Рецкер Я.И. Курс лекций по теории перевода [Текст] // М.: Изд-во І-го Московского пед. ин-та иностр. языков, 1968. - 160 с.

2. Влахов С., Флорин С. Непереводимое в переводе [Текст] / под ред. Вл. Россельса. - М.: Межд. отн., 1980. - 342 с.

3. Гольцекер Ю.П. Вопросы фразеологии и теория перевода (на материалах русско-польских и польско-русских переводов художественной прозы) [Текст]: Автореф. дисс. ... канд. филол. наук. - Минск, 1975. - 36 с.

4. Кунин А.В. Перевод устойчивых образных словосочетаний и пословиц с русского языка на английский [Текст] // Иностр. языки в школе, 1960, № 5. C.90-98.

5. Пастернак Б.Л. Детство Люверс [Текст] // Воздушные пути. Проза разных лет. - М.: Совет. писатель, 1982. - С.56-108.

6. Пастернак Б.Л. Доктор Живаго [Текст] // Избранное в двух томах. Т.2. - СПб.: Кристалл, 1998. - 560 с.

7. Федоров А.В. Основы общей теории перевода [Текст] - М.: Высш. школа, 1983. - 304 с.

8. Pasternak B. The Childhood of Luvers [Text] // The collected Prose works. Arrang. with an introduction by Stefan Schimanski. - London: Lindsay Drummond LTD., 1945. - P.165-214.

9. Pasternak B. Doctor Zhivago. [Text] / Transl. by M. Hayward and M. Harari, Collins and Harvill Press, London, 1958. - 510 p.

(c) Кожанова Лариса Владимировна (I.kozhanova@bk.ru). 